\title{
Planejamento Estratégico e Proatividade: um Estudo de Caso em Duas Unidades Regionais do Banco Central do Brasil
}

\author{
Antonio Francisco de Almeida
}

\section{ResUMO}

Este trabalho procura avaliar se o processo do planejamento estratégico no Banco Central do Brasil tem sido suficiente para tornar a organização mais proativa, usando para isso a aplicação de questionário ao corpo gerencial de duas unidades descentralizadas. O questionário já havia sido aplicado a uma das unidades, em 1995, após os desdobramentos do Encontro de Administração Estratégica, realizado em novembro de 1991. Nesta pesquisa, o questionário foi reaplicado em dezembro de 1998, desta vez em duas unidades, para avaliar os desdobramentos do Encontro Estratégico de abril de 1998, e comparar os resultados com a pesquisa de 1995. Assim, com um corte vertical no tempo (comparação das avaliações em uma mesma unidade, em dois momentos distintos), e com um corte horizontal na organização (comparação das avaliações de duas unidades no mesmo referencial temporal), pretende-se investigar a relação entre proatividade e o planejamento estratégico da instituição na perspectiva de duas unidades regionais.

Palavras-chaves: planejamento; estratégia; administração; gerenciamento.

\begin{abstract}
This paper evaluates if the process of strategic planning in Banco Central do Brasil has been sufficient, from a temporal perspective, to make the organization more proactive. Our focus was on two decentralized units, one of which replied a questionare given out in 1995 after the Meeting of Strategic Management of Banco Central do Brasil (November/1991). The questionare was handed out again in December/1998 to both organizational units, after the Meeting of Strategic Management in april/1998. Therefore, it was possible to evaluate the answers of one organizational unit at two distinct times and to compare the replies of two different units at the same moment.
\end{abstract}

Key words: planning; strategy; management; business. 


\section{INTRODUÇÃO}

O Banco Central do Brasil (BACEN), criado pela Lei 4.595, de 31/12/1964, é uma autarquia federal que integra o Sistema Financeiro Nacional (SFN). Tratase de uma organização com cerca de 4.000 servidores, com unidades distribuídas por diversas regiões do país. O BACEN é organizado com uma unidade especial e com departamentos centrais e unidades regionais. As atividades descentralizadas dos departamentos são coordenadas por esses e executadas pelas unidades regionais. Algumas atividades, como administração das reservas cambiais, operações de mercado aberto, renegociação de dívida externa, entre outras, são exercidas apenas por departamentos, enquanto as atividades de supervisão, meio circulante, registro e monitoramento de câmbio, dívida pública, atendimento ao público etc. são exercidas tanto por departamentos quanto por unidades regionais, sendo que aos primeiros cabem as funções de coordenação e acompanhamento das atividades, enquanto se encarregam da execução as unidades regionais.

No sentido de disseminar a cultura de planejamento como instrumento de gestão, além de outras iniciativas, destaca-se o Encontro de Administração Estratégica realizado em 1991, que definiu a missão e os objetivos da instituição, elencou as ameaças e oportunidades, os pontos fortes e fracos e explicitou ações e medidas de continuidade a serem implementadas, entre elas a realização do planejamento estratégico por área do banco, que neste trabalho será denominado de Planejamento Estratégico I. Em abril de 1998, o BACEN realizou novo encontro estratégico e, de maio a novembro de 1998, todas as unidades realizaram seus encontros táticos, tendo como premissas a missão, macroprocessos, objetivos e diretrizes da organização. Assim, cada uma das unidades procedeu ao levantamento de seu ambiente externo e interno e definiu metas e projetos para o triênio 1998/2001. O desdobramento desse trabalho será denominado nesta pesquisa de Planejamento Estratégico II.

Moraes (1995) realizou pesquisa sobre o planejamento estratégico no BACEN, abordando, entre outros aspectos, a questão da proatividade. Esse estudo utilizou documentos e arquivos da organização, bem como pesquisa com formulários e entrevistas. Destacam-se aqui alguns trechos, citados pelo autor, que foram obtidos dos seus trabalhos exploratórios:

"A condução deste Encontro foi baseada no conceito de que o Planejamento Estratégico, diferentemente do planejamento tradicional (de con- 
cepção reativa, que visa a adaptação da organização às mudanças do ambiente), deveria promover mudanças tanto na organização, como no meio em que atua (concepção proativa)".

"Há um esforço em direção à proatividade. O Banco Central sabe que precisa ser proativo. A própria adoção do Planejamento Estratégico é uma prova disso. Em algumas áreas o Banco consegue ser proativo, ainda que em pequena escala".

A pesquisa de Moraes (1995) abrangeu o corpo funcional da unidade regional do BACEN em Belo Horizonte, MG, com resultados apresentados por posições funcionais, incluindo gerentes e não gerentes. Após alguns anos da realização do trabalho de Moraes (1995), a instituição está passando por novo processo de planejamento estratégico, sendo que os resultados dos encontros estratégicos e táticos já estão consolidados, e as diversas unidades estão trabalhando nos seus planos operacionais. Assim, a presente pesquisa visa a responder à indagação:

\section{O exercício, ao longo do tempo, do processo de planejamento estratégico no Banco Central do Brasil tem sido suficiente para tornar a organização mais proativa?}

Dessa forma, o formulário relativo à proatividade, que fez parte da metodologia utilizada por Moraes (1995), foi reaplicado ao corpo gerencial da unidade estudada pelo autor. Foram comparados os resultados dos dois questionários, para validar ou não a hipótese de que o processo de planejamento estratégico auxilia a organização a ser mais proativa. Para enriquecer os elementos de análise, o questionário foi aplicado também na unidade regional em Salvador, BA.

\section{As Diferentes Abordagens da Literatura sobre Estratégia}

A palavra estratégia tem sido utilizada por milhares de anos, principalmente nos estudos militares; entretanto o conceito de estratégia na área de negócios e administração é relativamente recente. Dentre as inúmeras definições existentes, cita-se, como exemplo, aquela apresentada por Chandler (apud McCraw, 1998), que afirma que as decisões estratégicas dizem respeito às definições dos principais objetivos da empresa a longo prazo, enquanto Davidson (1988) afirma que estratégia é um curso específico de ação, que indica precisamente como uma empresa está utilizando os seus recursos com o fim de alcançar os seus objetivos pré-estabelecidos.

Os planos de longo prazo foram adotados, quando se acreditava que o futuro poderia ser previsto a partir da extrapolação do crescimento passado (Ansoff, 
1984). Bulgacov (1998) afirma que, no final da década de 50 e nos anos 60 , Ansoff enfocou a análise ambiental no desenvolvimento da estratégia empresarial, com conceitos básicos sobre sinergia e análise do ambiente. Na mesma época surgiu o planejamento estratégico, acompanhado do modelo SWOT (strenghs, weaknesses, opportunities and threats). O planejamento estratégico se apoiava na análise racional das ameaças e oportunidades do meio, dos pontos fortes e fracos da empresa e da escolha de estratégias, de forma a maximizar o cumprimento dos objetivos organizacionais. Para Horwitch (1988) o bom planejamento deveria não apenas ter algumas características essenciais como ser orientado para os objetivos e baseado na informação disponível e nas expectativas do ambiente, mas também cumprir de forma integrada funções básicas como obter resultados mediante a atribuição de responsabilidades e tarefas específicas.

Mintzberg (1990) afirma que no planejamento estratégico a estratégia é tomada como uma intenção deliberada, expressa por meio de um plano formal, resultante de intenso trabalho de análise. Neste estilo de gestão, as decisões estratégicas são tomadas pela alta gerência sem estarem diretamente relacionadas às operações necessárias para implantá-las, ou seja, ocorre um destacamento entre a formulação e a implementação da estratégia.

Enriquez (1997) esclarece que na fase do planejamento estratégico a estrutura tecnocrática via a racionalidade como ilimitada e o poder pertencente aos experts que possuem o conhecimento, o que lhes dava a possibilidade não somente de resolver de maneira ótima os problemas colocados, mas, igualmente, de antecipar o seu surgimento, graças a um sistema de previsão e de simulação, que permitia testar cenários, onde os únicos problemas interessantes eram aqueles quantificáveis, e as questões de ordem política não se colocavam. Para Cabral (1998), embora ricos em números, os planos mostravam-se pobres em estratégia. O planejamento tendia a tornar-se rígido e inflexível, em função de metas detalhadamente delimitadas. Os resultados negativos eram vistos como seqüelas da má implementação dos planos traçados.

Nas décadas de 70 e 80 surgem questionamentos a respeito da lógica daquilo que se convencionou chamar de época do planejamento estratégico. Alguns autores, entre eles o próprio Ansoff (1965), lançaram o debate de questões relativas a um novo arquétipo: o da gestão estratégica, que consiste na comunicação de uma visão estratégica global da empresa para os níveis hierárquicos inferiores, esperando-se que as iniciativas da empresa sejam coerentes com essa orientação geral. Para Hofer e Schendel (1978) a gerência estratégica é um processo de tratar "a dimensão empreendedora da organização, sua renovação e crescimento, usando de estratégias para guiar as operações”. Assim, é necessário ante- 
cipar mudanças por um tipo de long-term vision, ou ter uma capacidade de resposta às mudanças nos ambientes de negócios (Quintella e Dias, 1997). Para Collins e Porras (1996) as empresas que alcançam o sucesso possuem um "corpo de valores e propósitos" que se mantém fixo, enquanto suas estratégias de negócio se adaptam a um mundo em mudanças. Hickman e Silva (1984) definem visão como sendo "uma jornada do conhecido para o desconhecido, criando o futuro a partir de uma montagem de fatos, esperanças, sonhos, perigos, e oportunidades correntes". Cabral (1998) define o estilo de visão como parte da crença de que a melhor forma de se predizer o futuro é inventá-lo. O sucesso, individual ou organizacional, depende da habilidade de antecipar o futuro e participar das mudanças por vir. Organizações com uma clara visão de futuro têm maiores chances de garantir vantagens competitivas e liderança de mercado.

Ansoff (1978) abordou a escalada da turbulência do ambiente no século XX, afirmando que as firmas se encontram na incômoda situação em que o tempo disponível se tornou mais curto e o tempo necessário para uma resposta eficaz se tornou mais longo. Ansoff e McDonnell (1984) afirmaram que a potencialidade da administração de uma organização é determinada por cinco fatores que interagem mutuamente: qualificação e mentalidade dos principais administradores; clima e cultura organizacional; estrutura de poder; sistemas e estrutura organizacional; e capacidade da administração geral para o trabalho de gestão. Dessa forma, a administração estratégica é uma abordagem sistemática da gestão de mudanças, que envolve o planejamento das potencialidades, procurando respostas em tempo real mediante a administração de questões estratégicas e gestão da resistência durante a implantação da estratégia. A agressividade estratégica de uma organização está relacionada ao seu potencial de adaptação às mudanças, seja de forma reativa, antecipatória, inovadora ou criativa. O sucesso estratégico é alcançado pela otimização do potencial de desempenho, tendo como uma de suas premissas a necessidade de que a agressividade do comportamento da organização se equipare à turbulência do ambiente. Assim, Ansoffe McDonnell (1984) identificaram cinco níveis de turbulência do ambiente e cinco níveis correspondentes de agressividade estratégica, apresentados no Quadro 1.

\section{Quadro 1: Turbulência Ambiental e Agressividade Estratégica}

\begin{tabular}{|c|c|c|c|c|c|}
\hline N ível & 1 & 2 & 3 & 4 & 5 \\
\hline T urbu lência & R epetitiv a & C rescente & M utável & D escontínua & S u rp reendente \\
\hline $\begin{array}{l}\text { A gressividade } \\
\text { estratégica }\end{array}$ & $\begin{array}{l}\text { E stável } \\
\text { B a seada em } \\
\text { precedentes }\end{array}$ & $\begin{array}{l}\text { R eativa } \\
\text { G radativa } \\
\text { B aseada na } \\
\text { experência }\end{array}$ & $\begin{array}{l}\text { A ntec ṕ ató ria } \\
\text { G rada tiva } \\
\text { B a sead a em } \\
\text { extrapo bção }\end{array}$ & $\begin{array}{l}\text { Em preend ed ora } \\
\text { D e scontínua } \\
\text { B a seada no } \\
\text { futuro e sp erado }\end{array}$ & $\begin{array}{l}\text { C riativa } \\
\text { D escontínua } \\
\text { B aseada na } \\
\text { criatividade }\end{array}$ \\
\hline
\end{tabular}


$\mathrm{Na}$ abordagem proposta por Ansoff e McDonnell (1984), o potencial de desempenho é função da capacidade de reação da organização em face da agressividade de sua estratégia. O que se observa dessa abordagem é que o ambiente no qual a organização se insere e a sua capacidade em reagir às turbulências desse ambiente influenciam nas decisões estratégicas. Dessa forma, ambientes com nível de turbulência entre 4 e 5 exigirão por parte da organização uma agressividade estratégica empreendedora e criativa.

Gimenez (1998) assinala que Miles e Snow (1978) produziram uma taxonomia do que chamaram estratégias competitivas, em oposição às estratégias corporativas. Estratégias corporativas dizem respeito às decisões relacionadas ao tipo de negócio no qual a empresa deve atuar, estratégias competitivas relacionam-se à forma como a organização compete em determinado negócio. Gimenez et al. (1998) assinalam que, entre as diversas taxonomias existentes para estratégia, a proposta por Miles e Snow (1978) tem tido ampla aceitação na área de administração estratégica. Miles e Snow (1978) propõem a existência de quatro tipos de estratégias genéricas: defensiva (manter uma linha de produtos ou serviços), prospectiva (inovar produtos ou serviços), analítica (meio termo entre a defensiva e a prospectiva) e reativa (reagir ao ambiente).

Porter (1986) apresenta um modelo para a análise de estratégias competitivas, baseado em cinco dimensões: a ameaça de novos entrantes; o poder de barganha dos fornecedores; a ameaça de produtos e serviços substitutos; o poder de barganha dos clientes; a rivalidade entre os competidores. Nogueira e Moreira (1998) destacam que, segundo Porter (1986), o estrategista deve avaliar cada uma dessas dimensões e traçar um plano de ação que incluirá o posicionamento da empresa, de forma que as suas capacitações forneçam as melhores defesas contra as forças competitivas, permitindo influenciar o equilíbrio dessas forças por meio de movimentos estratégicos, a fim de que melhore a posição competitiva da empresa e antecipe mudanças nos seus fatores subjacentes. Em trabalho mais recente Porter (1996) destaca que a busca de eficiência operacional, embora necessária, não é estratégia. Para o autor a estratégia competitiva significa uma escolha deliberada de um conjunto diferenciado de atividades, em relação aos concorrentes, para a entrega de um produto ou serviço de valor único, o que, em outras palavras, pode ser definido também como o posicionamento estratégico.

Mintzberg (1990) argumenta que a passagem do planejamento estratégico para a gestão estratégica não implicou, necessariamente, alguma mudança radical em termos do pensamento sobre estratégia organizacional. Os teóricos da gestão estratégica acreditam ser possível posicionar-se de maneira ótima num ambiente de alta turbulência; no entanto Mintzberg (1990) classificou essa visão como a "falácia da previsibilidade". Para ele, a literatura característica dessa corrente, 
que é vastíssima, adota um enfoque essencialmente prescritivo (Porter, Ansoff, Hofer e Schendel, Miles e Snow etc.). O que ocorreu, em verdade, foi a incorporação do planejamento estratégico à gestão estratégica, como um de seus componentes ou ferramentas, deixando o primeiro de ser o elemento principal do processo, ou a sua matriz. Mintzberg (1994) aponta dois outros problemas: o destacamento (separação entre formulação e implementação, ou entre pensar e fazer) e a formalização (rotinas do planejamento).

Assim, Mintzberg e Waters (1985) definem as estratégias emergentes, em contraposição às estratégias deliberadas, como sendo aquelas estratégias formadas (que emergem) na organização, na ausência de uma intenção prévia. Mintzberg e Waters (1985) concluem que é possível que um processo de formulação de estratégia altamente deliberado, ou seja, planejado em detalhes, vá desviar a organização de atividades prospectivas, enquanto que as estratégias emergentes não.

Na direção das estratégias emergentes de Mintzberg e Waters (1985), pode ser identificada uma abordagem na literatura produzida sobre estratégia: é a que trata de estratégias processuais, em que a estratégia é processo de aprendizagem, ou padrão de evolução, ao invés de plano formal, ligado a um ambiente de mudanças incrementais. Nessa abordagem, estratégia é um caminho que envolve modificações, sincronicidade, e flexibilidade, incorporando temas como o aprendizado organizacional e o desenvolvimento de competências essenciais (Lauriol, 1996). Esse enfoque, menos prescritivo e essencialmente descritivo, entende a estratégia como caminho em construção, calcado no aprendizado e que contempla diversos atores estratégicos.

A estratégia tateante, descrita nos trabalhos de Avenier $(1996,1997)$, guarda pontos de semelhança com as estratégias emergentes de Mintzberg e Waters (1985), uma vez que se baseia num padrão evolutivo de ações, flexível e sujeito a alterações ao longo do tempo. Para Avenier (1997) a estratégia tateante é caracterizada pela possibilidade de múltiplas idas e vindas entre a visão estratégica (visão de futuro que se deseja construir em algum nível) e as ações estratégicas (ações de mudança concebidas em relação a uma determinada visão estratégica). Percebe-se que, segundo a prática da estratégia tateante, uma ação estratégica não deixa de apresentar caráter intencional; entretanto há flexibilidade para que novos elementos sejam considerados ao longo do percurso, o que demostra a inclusão da noção de aprendizado (Fischer e Guanais, 1998).

$\mathrm{Na}$ abordagem da estratégia tateante existe a possibilidade do diálogo entre as ações locais e as visões globais. Ou seja, numa estratégia tateante há espaço para que iniciativas de sucesso localizadas possam ser objeto de reflexão, a fim de que se tornem base para as futuras intenções de sucesso de toda a organização. A 
estratégia tateante leva em consideração o aprendizado ao longo do percurso, o que caracteriza uma visão de mundo construtivista. Enquanto a estrutura rígida do planejamento estratégico parte de objetivos estabelecidos inicialmente a fim de conciliar o ambiente interno e externo da organização, as estruturas flexíveis de uma estratégia tateante permitem que iniciativas de sucesso locais possam vir a ser difundidas de tal modo que se tornem o padrão de ação de toda a organização. Alguns exemplos de disposições organizacionais favorecem a aplicação de uma estratégia tateante, com ênfase na criação de espaços de debate intra-unidades, interunidades e interníveis, a fim de que ações estratégicas locais possam tornar-se mais facilmente visões estratégicas globais. A atividade de planejamento estratégico, por exemplo, pode ser um grande espaço de debate, desde que na sua elaboração haja envolvimento maior dos membros da organização. A implantação de um sistema de informação organizacional também pode favorecer o processo de formação de estratégias, permitindo a difusão das iniciativas por toda a organização, possibilitando a comunicação dos sucessos de uma unidade para outra, ou de uma unidade para a alta gerência (Avenier, 1997).

Cabral (1998) ressalva que a maioria dos enfoques do pensamento administrativo ainda tende a privilegiar os processos analíticos, racionais e estruturados; no entanto vários autores têm destacado a necessidade de dar importância a insights, criatividade, aprendizagem, inovação, e de habilidades relacionadas às pessoas (Peters e Waterman, 1982).

Assim, percebe-se que as idéias apresentadas nos trabalhos de Avenier (1996, 1997) estão em sintonia com os estudos sobre organizações aprendizes. Para Senge (1990) organizações de aprendizagem são aquelas nas quais as pessoas expandem continuamente sua capacidade de criar os resultados que realmente desejam, onde surgem novos e elevados padrões de raciocínio, cuja aspiração coletiva é libertada e cujas pessoas aprendem continuamente a aprender em grupo. Argyris e Schon (1993) argumentam que toda a ação deliberada tem base cognitiva, que ela reflete normas, estratégias e considerações ou modelos do mundo que reclamam por uma validação geral. Como conseqüência, o aprendizado humano precisa ser entendido como a construção, teste e reestruturação de certo tipo de conhecimento. A ação e o aprendizado humano podem ser colocados no contexto maior do conhecimento. Muitos dos termos aplicados para indivíduos são usados por Argyris e Schon (1993) em metáforas da organização. Fala-se sobre ação e comportamento organizacional, inteligência e memória organizacional, que as organizações aprendem ou falham no aprendizado etc.

A habilidade da organização em permanecer estável em um contexto de mudanças denota um tipo de aprendizado, chamado por Argyris e Schon (1993) de aprendizado de circuito simples. Existe um malha de realimentação que conecta os resultados detectados pela ação da estratégia organizacional e pelas modifi- 
cações de suposições, com o intuito de manter o desempenho organizacional dentro dos limites da faixa definida pelas normas organizacionais. Chama-se aprendizagem por circuito duplo aquelas espécies de indagações organizacionais que resolvem as incompatibilidades das normas da organização, estabelecendo novas prioridades e pesos, ou reestruturando as normas juntamente com as hipóteses e estratégias associadas.

Mas é importante não se perder de vista o ciclo do aprendizado organizacional como um processo dialético, pois novas condições propícias a erros podem emergir como resultado do aprendizado. O objetivo da organização é manter a estabilidade para alcançar a sobrevivência. Nas organizações, o requisito do aprendizado e das mudanças em circuito duplo é de especial importância, pois o ambiente externo tende a ser dinâmico e o ambiente interno é basicamente instável; no entanto o aprendizado em circuito duplo provoca indagações sobre as normas instituídas, o que pode resultar em alguns riscos.

O caminho do aprendizado pode ser facilitado pelo desenvolvimento de estruturas apropriadas para a aprendizagem e de modos para o conhecimento organizacional. Existem importantes interações do sistema de aprendizado com a estrutura organizacional. Entenda-se por estrutura não apenas os padrões de regras implícitas em um sistema organizacional de tarefas, mas também os padrões e o fluxo da informação que o sistema de tarefas envolve e é alimentado. A intervenção estrutural não é suficiente para permitir o aprendizado organizacional, mas a estrutura pode impedir ou facilitar esse processo.

Em organizações de grande escala, cujas tarefas envolvem um alto grau de variedades, incertezas e complexidades, existem inevitáveis requisitos para o gerenciamento descentralizado; no entanto, alguns cuidados devem ser tomados pela administração central, para evitar que sejam criadas incongruências, como, por exemplo, o estabelecimento de padrões de desempenho e de reconhecimento que gerem conflitos de interesse, impedindo o trabalho em conjunto e as contribuições entre as unidades de uma mesma organização. Assim, um campo de pesquisa apropriado é o desenvolvimento de sistemas de informações que permitam compatibilizar o processo de aprendizado organizacional e a definição da estrutura da memória da organização (Argyris e Schon, 1993).

Morgan (1995) identifica algumas dificuldades para as organizações aprendizes. Existe um perigo de não se levar em conta conflitos entre os requisitos da aprendizagem e construção da organização aprendiz, por um lado, e das realidades de poder, por outro. Qualquer movimento para fora da burocracia tem maiores implicações para a distribuição de poder, uma vez que a autonomia devotada à organização aprendiz mina essa estrutura. Além disso, o processo de aprendizagem requer um grau de abertura que é estranho às maneiras tradicionais de 
administração. Outra limitação é que qualquer movimento no sentido da organização aprendiz é acompanhado por mudanças de atitudes e valores, sendo que as realidades do poder podem ser reforçadas pela inércia que vem das suposições e crenças existentes. Acrescenta-se aqui o fato de que não existe uma forma de se indicar o tempo necessário para que uma organização se transforme em organização aprendiz; as ferramentas para a transformação não são pragmáticas. Existem apenas recomendações, como encorajar abertura e flexibilidade, aceitar incertezas e erros, incentivar discussão dos problemas sob diferentes pontos de vista, dirigir esforços para a investigação, criar estruturas e processos organizacionais favoráveis à aprendizagem como descentralização, criação de estruturas matriciais etc.

No referencial sobre estratégia, destaca-se também as abordagens de Prahalad e Hamel (1990). Os autores afirmam que muitas companhias estão despendendo grande quantidade de energia simplesmente para reproduzir as vantagens de qualidade e custo apresentadas por seus concorrentes globais. A partir de conceitos como segmentação, cadeia de valores, comparação com o concorrente, grupos estratégicos, barreiras à mobilidade, muitos empresários tornaram-se cada vez melhores em elaborar mapas da indústria, enquanto seus concorrentes têm reorganizado continentes inteiros. Hamel (1996) afirma que em sua vasta maioria as companhias vêem o planejamento estratégico como um ritual tendendo a ser reducionista, baseado em regras e heurísticas simples, assumindo o futuro como uma projeção do presente. A meta estratégica não é achar um nicho de mercado, mas sim criar um novo espaço, que não se encontra no mapa, adequado às forças da companhia. Prahalad e Hamel (1990) afirmam que as estratégias devem ser focalizadas nas competências essenciais da organização (core competences), procurando aprimorar o que a organização efetivamente sabe fazer. Uma competência essencial deve ser de difícil imitação e formar uma complexa harmonização das tecnologias e habilidades de produção, fazendo uso até mesmo de alianças. Na sua noção de estratégia como um intento, Hamel e Prahalad (1989) defendem o estabelecimento de um objetivo estratégico, afirmando que as companhias que chegaram à liderança global começaram com ambições desproporcionais aos seus recursos e capacidades, criando uma obsessão de vencer em todos os níveis da organização. Os autores afirmam ainda que a estratégia precisa ser vista de forma revolucionária, argumentando que não existe forma padronizada de se fazer isso, embora alguns princípios possam ser aplicados, como a democratização do processo de formação da estratégia, bem como a ampliação e aprofundamento desse processo, para garantir diversidade de perspectiva e ao mesmo tempo unidade de proposta, entre outros. 


\section{Metodologia Adotada}

Moraes (1995) realizou pesquisa em que busca descrever os processos de elaboração estratégica do BACEN e da Unidade Regional do Banco Central em Belo Horizonte, MG (DEBHO). Entre as características estudadas pelo autor, destaca-se aqui a questão da proatividade. Em seu trabalho exploratório Moraes (1995) investigou a seguinte hipótese:

\section{Os processos de elaboração estratégica do BACEN [e da DEBHO] têm sido suficientemente efetivos para permitir que a organização responda ao ritmo das mudanças ambientais, conforme percepção do corpo funcional da Unidade Regional em Belo Horizonte.}

A hipótese acima foi rejeitada na pesquisa de Moraes (1995), que utilizou formulário com as afirmativas abaixo (Q1_1 a Q1_4), apresentadas aos funcionários da $\mathrm{DEBHO}$, utilizando a seguinte referência: $\mathrm{CT}=$ Concordo totalmente; $\mathrm{C}=$ Concordo; $\mathrm{N}=$ Não concordo nem discordo; $\mathrm{D}=$ Discordo; $\mathrm{DT}=$ Discordo totalmente. As avaliações de cada afirmativa foram convertidas em pontos (em uma escala de 1 a $5^{(1)}$ ), com dados obtidos entre funcionários que ocupavam ou não cargo gerencial, e foi computado um score, calculado da seguinte forma:

Score $=\left(\mathrm{Q} 1 \_1+\mathrm{Q} 1 \_2+\mathrm{Q} 1 \_3+\mathrm{Q} 1 \_4\right) / 4$

Q1_1. O planejamento estratégico realizado pelo BACEN tem sido suficiente para a organização se preparar para as mudanças no ambiente e não correr riscos de ser atropelada por elas.

Q1_2. O planejamento realizado pela DEBHO tem sido suficiente para a unidade se preparar para as mudanças no ambiente e não correr riscos de ser atropelada por elas.

Q1_3. Na área específica em que atuo, o BACEN está preparado para mudanças futuras na realidade brasileira e mundial.

Q1_4. As decisões centrais são tomadas em função das demandas imediatistas do Governo e da sociedade e, com isso, estamos sempre apagando incêndio.

Como os resultados da pesquisa de Moraes (1995) tiveram de se restringir a um único processo de planejamento estratégico, não foi possível analisar se a experiência, ao longo do tempo, de outros processos de planejamento estratégico, levaria a uma mudança de avaliação dos funcionários da DEBHO quanto à proatividade e ao processo de elaboração estratégica do banco. Assim, com este 
trabalho, procurou-se investigar essa possível mudança de avaliação; as afirmativas acima foram reapresentadas, em dezembro de 1998, ao corpo gerencial da Unidade Regional do BACEN em Belo Horizonte. Com isso, espera-se responder à seguinte pergunta:

\section{O exercício, ao longo do tempo, do processo de planejamento estraté- gico no Banco Central do Brasil tem sido suficiente para tornar a organização mais proativa?}

Dessa forma, pretende-se comparar os resultados dos dois formulários aplicados em diferentes instantes de tempo, sendo que o primeiro após o Planejamento Estratégico $I^{(2)}$ (1991), na pesquisa de Moraes (1995); o segundo, em dezembro de 1998 (aplicado para realização deste trabalho), após o Encontro Estratégico de abril de 1998, que foi desdobrado no Planejamento Estratégico II.

As ações do planejamento estratégico não obedeceram a uma rotina de continuidade. Após o Encontro de Administração Estratégica de novembro de 1991, as várias ações se desdobraram até 1995 com o acompanhamento dos planos operacionais das diversas unidades do banco. Os anos de 1996 e 1997 experimentaram uma paralisação das atividades de planejamento estratégico (o que não significou que as unidades fossem impedidas de realizar atividades de planejamento), tendo em vista que a organização desenvolveu projeto conhecido internamente como modernização organizacional, contando com consultoria externa e envolvimento de todas as unidades da instituição, tendo como um dos objetivos uma nova estrutura para o banco. $\mathrm{O}$ fato de haver um intervalo de tempo relativamente longo entre os planejamentos estratégicos do BACEN é um fator que pode influenciar a avaliação dos entrevistados.

Como se afirmou anteriormente, em abril de 1998 a organização realizou encontro estratégico, que resultou no desdobramento do Planejamento Estratégico II. Como os desdobramentos do processo ainda não haviam chegado ao nível operacional, na realização deste trabalho, a grande parte dos servidores envolvidos, até então, eram aqueles com funções gerenciais. Dessa forma, os questionários foram entregues apenas a esses funcionários. Uma vez que os dados apresentados por Moraes (1995) foram produzidos por gerentes e não gerentes, a análise comparativa pôde ser realizada. Dessa forma, os dados comparativos de ambos os formulários foram utilizados para investigar a seguinte hipótese:

Houve uma mudança positiva de avaliação do score proatividade, relacionado ao Planejamento Estratégico I, por parte dos servidores que ocupam funções gerenciais na DEBHO, após a realização do Planejamento Estratégico II. 
O formulário foi aplicado também à Unidade Regional do Banco Central em Salvador, BA (DESAL), permitindo, além de uma análise de corte vertical no tempo (comparação das respostas da DEBHO em momentos distintos), uma análise de corte horizontal na organização (comparação das respostas de duas unidades descentralizadas distintas, DEBHO e DESAL), para verificar a existência de possível viés de análise que poderia vir a ser atribuído à DEBHO.

Uma vez que as respostas aos quesitos relativos à proatividade guardam relação com a importância que cada entrevistado atribui ao planejamento estratégico, procurou-se investigar também essa questão, apenas com o objetivo de complementar a análise, sem discuti-la profundamente, tendo em vista que o escopo desta pesquisa foi avaliar a proatividade e não a importância do planejamento. Assim, foi usado o formulário abaixo, utilizado por Moraes (1995) e reaplicado nesta pesquisa com pequenas adaptações, preservando a escala de avaliação apresentada pelo autor, para evitar problemas de comparação dos resultados passados e atuais:

"Favor avaliar a importância de cada item abaixo, em termos de referência/ impacto no trabalho propriamente dito e na gestão da instituição, em uma escala de 1 (menor importância) a 6 (maior importância):

\section{Q2 1. Missão do BACEN.}

Q2_2. Objetivos estratégicos do BACEN.

Q2_3. Planejamento Estratégico do BACEN, realizado pela reunião da Diretoria em $3 / 4 / 98$.

Q2_4. Planejamento Tático realizado pelos Departamentos Centrais e pelas Unidades Regionais em 1998.

Q2_5. Atividades de planejamento desenvolvidas pela unidade regional em geral".

Para realizar esta pesquisa foram distribuídos por meio de correio eletrônico, em dezembro de 1998, 34 questionários para os funcionários que ocupam funções gerenciais na DEBHO, e foram recebidas 16 respostas, o que representa cerca de $47 \%$ da população gerencial da DEBHO. Para a DESAL foram distribuídos 25 questionários, sendo obtidas 18 respostas, ou $72 \%$ do universo gerencial da DESAL. As amostras foram consideradas representativas, uma vez que Moraes (1995) obteve um índice de resposta de 52,1\% do total de servidores da unidade regional. 


\section{AnÁlise dos Resultados}

No Quadro 2 encontram-se os resultados das avaliações relativas à proatividade. Na primeira linha (DEBHO_1) estão os resultados encontrados por Moraes (1995) nas suas entrevistas do Planejamento Estratégico I, na Unidade Regional do Banco Central em Belo Horizonte. Na segunda linha (DEBHO_2) estão os resultados relativos ao Planejamento Estratégico II da DEBHO, e na última linha (DESAL) estão os resultados encontrados para o Planejamento Estratégico II da Unidade Regional do Banco Central em Salvador.

\section{Quadro 2: Avaliações às Afirmativas sobre Proatividade}

\begin{tabular}{l|cccc|c}
\hline PE./A fim a tiva & $\ell 1_{-} 1$ & $011_{-}$ & $011_{-} 3$ & $\ell 1_{-} 4$ & Score \\
\hline DEBH 0_1 & 2,32 & 2,96 & 2,46 & 2,24 & 2,50 \\
(ano de 1995) & & & & & $(0,49)$ \\
DEBH 0_2 & 2,44 & 3,00 & 2,38 & 1,81 & 2,41 \\
(em dez/1998) & $(1,03)$ & $(1,15)$ & $(0,89)$ & $(0,66)$ & $(0,58)$ \\
D E S A L & 3,17 & 3,17 & 3,11 & 1,61 & 2,77 \\
(em dez/1998) & $(1,15)$ & $(1,25)$ & $(1,32)$ & $(0,78)$ & $(0,85)$ \\
\hline
\end{tabular}

Obs: Os números entre parêntesis são os erros padrões amostrais.

Relativamente às afirmativas sobre proatividade Q1_1 e Q1_3, percebe-se que as médias associadas aos desvios padrões revelam que praticamente não houve mudança significativa de avaliação dos funcionários da DEBHO ao longo do tempo, sendo que há uma tendência à discordância quanto às afirmativas, por parte dos gerentes da DEBHO. Vale destacar que no período entre os dois processos de planejamento estratégico o BACEN passou por uma série de mudanças, inclusive no seu quadro de pessoal; mas mesmo com uma alteração de parte do quadro gerencial e com as turbulências e ocorrências no período, não houve modificação significativa da avaliação dos gerentes quanto às duas afirmativas. A DESAL avaliou os dois itens de forma neutra, não se distanciando muito da avaliação da DEBHO, num nível de confiança de $95 \%$, bicaudal, para testes de hipótese de comparação das médias dos valores atribuídos às questões pelas duas unidades regionais com estatística $\mathrm{t}=1,89$ para $\mathrm{Q} 1$ _1 e estatística $\mathrm{t}=1,85$ para Q1_3.

Com relação à afirmativa sobre proatividade Q1_2, percebe-se uma neutralidade das respostas (média próxima a 3), confirmando a própria avaliação da 
DEBHO ao longo do tempo (DEBHO_1 e DEBHO_2), e a ratificação dessa avaliação pelos funcionários da DESAL.

A análise das respostas à afirmativa Q1_4 constata que ambas as unidades possuem a avaliação de que o Banco Central do Brasil age em resposta às demandas imediatistas do Governo e da sociedade. Vale lembrar que as notas foram atribuídas a esse item de forma inversa daquela dos demais. Assim, quanto menor o valor observado, maior a concordância com o item.

A coluna score do Quadro 2 consolida as avaliações relativas à questão da proatividade. Dessa forma, rejeita-se a hipótese anteriormente levantada, pois se observa que não houve mudança significativa da avaliação dos funcionários da DEBHO, relativamente ao item, mantendo-se uma posição entre discordância e neutralidade. Isso permite concluir que em resposta à pergunta levantada neste trabalho, apresentada anteriormente, pode-se afirmar que, conforme a avaliação dos funcionários que ocupam funções gerenciais na DEBHO, não existe concordância de que o exercício, ao longo do tempo, do planejamento estratégico é suficiente para tornar a organização mais proativa. A avaliação ficou entre uma posição de neutralidade e uma posição de discordância. Além disso, os resultados do corte horizontal na organização (avaliação da DESAL) ratificam os valores absolutos da avaliação da DEBHO. Isso indica que, aparentemente, não existe um viés de análise da Unidade Regional em Belo Horizonte, em relação ao valor absoluto desses scores.

Finalmente, o Quadro 3 apresenta a consolidação das respostas às questões relativas à importância atribuída ao planejamento estratégico. Embora os resultados anteriores indiquem uma posição entre neutralidade e discordância de que o planejamento estratégico seja visto como suficiente para que a organização seja mais proativa, o Quadro 3 revela que ele é visto pelo corpo gerencial das duas unidades regionais do BACEN como ferramenta importante para a instituição (um score médio em torno de 4,5, em uma escala de 1 a 6 ).

Quadro 3: Importância do Planejamento Estratégico

\begin{tabular}{|c|c|c|c|c|c|c|}
\hline P E ./Q uestão & $22_{-} 1$ & $22_{-} 2$ & $22-3$ & $Q_{2} 24$ & $22-5$ & Score \\
\hline DEBH $O_{-} 1$ & 4,63 & 4,85 & 3,68 & 3,62 & 4,96 & 4,35 \\
\hline \multirow[t]{2}{*}{$\mathrm{DEBHO} \mathrm{C}_{-} 2$} & 4,69 & 4,81 & 4,56 & 4,88 & 4,44 & 4,68 \\
\hline & $(1,58)$ & $(1,22)$ & $(1,26)$ & $(1,20)$ & $(1,55)$ & $(1,16)$ \\
\hline \multirow[t]{2}{*}{ D E S A L } & 5,11 & 4,56 & 4,06 & 4,00 & 3,94 & 4,33 \\
\hline & $(1,18)$ & $(1,20)$ & $(1,21)$ & $(1,28)$ & $(1,80)$ & $(1,12)$ \\
\hline
\end{tabular}

Obs: Os números entre parêntesis são os erros padrões amostrais. 
Na resposta aberta de um dos entrevistados, que encaminhou comentários adicionais aos formulários, por iniciativa própria, pode-se observar como os resultados encontrados por esta pesquisa estão de acordo com sua avaliação quanto à proatividade e importância.

"O planejamento estratégico tem ajudado muito ao banco como instituição, apesar de entender que não tem sido suficiente ou talvez não esteja acontecendo como deveria ser, num nível de profundidade e abrangência maiores. Penso que a parte de prospecção (pensar o futuro) deveria ser mais explorada, ou seja, como deve ser o Banco Central do Brasil amanhã, daqui a um ano, dois anos, dez anos. Como a sociedade brasileira quer o nosso Banco Central (aí entendida a sociedade como os vários segmentos que têm representação, além dos poderes da República). Principalmente, como o BACEN vai ter sua presença nas áreas geográficas do país, como será a atuação dessa representação etc".

É importante que se façam algumas considerações antes de iniciar uma análise mais detalhada dos resultados. O BACEN passou por algumas modificações internas ao longo dos últimos anos, dentre elas a mudança do regime jurídico dos servidores, grande número de aposentadorias, alterações de estrutura organizacional etc. Aliado a isso, o ambiente externo é muito turbulento, sendo que a instituição é demandada constantemente a se envolver em ações governamentais ligadas à política monetária e cambial, além de outras demandas como o PROER, reestruturação da dívida externa etc. Como se afirma na introdução, as unidades do banco são divididas em departamentos centrais e unidades regionais. As primeiras são responsáveis pela formulação de normas, elaboração de diretrizes e acompanhamento das atividades de execução que são realizadas nas unidades regionais. Sem dúvida, a turbulência do ambiente externo exerce efeitos mais intensos nos departamentos centrais do que nas unidades regionais; mesmo assim, essa turbulência permeia toda a organização. O processo de planejamento estratégico envolve tanto os departamentos como as unidades regionais, sendo que essas últimas atuam diretamente no sistema financeiro, tendo em vista suas atribuições de execução das tarefas descentralizadas, agindo como um elemento de percepção do funcionamento desse sistema. Vale destacar também que o BACEN é uma autarquia vinculada ao Ministério da Fazenda, sendo que sua atuação não é autônoma. Essa falta de autonomia deve ser levada em consideração, quando se analisa a resposta à questão Q1_4.

O Planejamento Estratégico II do Banco Central do Brasil foi realizado a partir da definição, pela diretoria da instituição, da sua missão, dos seus macroprocessos, vistos como grandes atividades fins do banco, dos seus objetivos estratégicos e de suas diretrizes. Além disso, foram levantados itens a serem contem- 
plados na definição das metas e dos projetos das unidades. A partir dos resultados do encontro estratégico, tiveram início os chamados encontros táticos, contemplando as unidades do banco (centrais e regionais), contando com a participação do corpo gerencial. Os encontros estratégico e táticos foram feitos levando em consideração o modelo SWOT, onde foram levantadas as forças e fraquezas da organização, bem como as oportunidades e ameaças.

Percebe-se que o enfoque do Banco Central do Brasil privilegiou um processo analítico, racional e estruturado, o que, aliás, conforme observou Cabral (1998), ainda é o enfoque mais utilizado pelas organizações; no entanto, retornando à análise ao Quadro 1, poder-se-ia indagar qual o nível de turbulência ambiental avaliado para o BACEN. Levando em consideração a dinâmica do setor financeiro, a internacionalização da economia, a entrada de bancos estrangeiros no país, riscos de crises financeiras sistêmicas, percalços na política monetária e cambial, perspectiva de reforma administrativa do Estado com a possível transformação do Banco Central do Brasil em Agência Executiva, lançamento de novos produtos como os derivativos, a utilização da moeda virtual, a formação de blocos econômicos etc., é difícil imaginar uma classificação de turbulência ambiental para o BACEN que não seja no mínimo 4 (turbulência descontínua), o que exigiria por parte da organização um comportamento empreendedor e até mesmo criativo.

A palavra empreender (nível de turbulência 4, do Quadro 1) está associada a ser ativo, arrojado, que se aventura à realização de coisas difíceis, enquanto a palavra antecipar (nível de turbulência 3) está associada a fazer alguma coisa antes do momento próprio. No nível de turbulência 3, a expectativa é de que as mudanças ocorram de forma gradativa e que, assim, haja certo grau de previsibilidade. O prefixo pro tem origem grega e entra na composição dos vocábulos com o sentido de diante, para diante, anteriormente etc. Dessa forma, ser proativo é estar na frente dos acontecimentos, o que é postura importante em ambiente turbulento. Como se viu nos resultados da pesquisa, o planejamento estratégico do Banco Central do Brasil, por si só, não é percebido por seus funcionários como efetivo na construção de uma organização proativa, não obstante se reconheça a sua importância para a organização.

O reconhecimento dessa importância era esperado, uma vez que o planejamento estratégico é relacionado com a palavra estratégia, e essa, por sua vez, conforme observa Quintella (1993), foi interpretada por Ansoff (1965) como algo pertencente à relação entre a empresa e seu meio, sugerindo que esta definição é diferente daquela de uso corrente em que estratégico é usualmente empregado como sinônimo de importante. Acredita-se aqui, que justamente essa idéia de uso corrente é um dos fatores, porém não o único, que faz com que o planejamento estratégico seja visto como algo importante pela organização. 
Além disso, o planejamento estratégico é uma forma de a organização estabelecer uma missão, visão, objetivos e metas e desenvolver planos para alcançálos. Esse processo apresenta como ponto positivo o fato de se tornar um instrumento de visibilidade e comprometimento dentro da organização, podendo ser um grande espaço de debate, desde que na sua elaboração haja envolvimento dos membros da instituição, para evitar a idéia de separação (falácia do destacamento de Mintzberg) entre a formulação e a implementação; mas o seu caráter estritamente racional, formal e analítico, conforme criticam alguns autores, como Mintzberg (1990), pode redundar em perda na capacidade de prospecção. Os resultados desta pesquisa apontam na direção da crítica apresentada por Mintzberg (1990), uma vez que o planejamento estratégico parece não estar contribuindo muito para que a organização seja mais proativa.

A interpretação entre neutralidade e discordância, quanto à suficiência do planejamento estratégico no BACEN para tornar a organização mais proativa, pode estar vinculada, entre outros fatores, a um descontentamento por parte da gerência no atinente aos aspetos formais do processo de planejamento estratégico: ela acredita que esse deveria privilegiar mais a prospecção, fomentando a discussão de como deve ser o BACEN do futuro, o que a sociedade espera de sua atuação etc. Ainda assim, a evolução do pensamento sobre estratégia, apresentada no item 2 deste trabalho, indica que o processo de planejamento estratégico não pode ser visto como a única ferramenta, ou o instrumento mais adequado para $\mathrm{o}$ desenvolvimento da estratégia da organização.

Como se viu anteriormente, os autores que percebem que a estratégia é um processo de aprendizagem ao longo do percurso, como Avenier (1997), defendem que a organização precisa criar espaços de debate intraunidades, interunidades e interníveis, a fim de que ações estratégicas locais possam tornar-se mais facilmente visões estratégicas globais. Na verdade, a aprendizagem necessita de um modelo de gestão organizacional que viabilize tal processo. Nesse modelo de gestão, a estabilidade organizacional é alcançada pelo aprendizado em circuito simples, de Argyris e Schon (1993), por uma comparação dos resultados alcançados com aqueles esperados, estabelecidos pelas normas e processos de planejamento, enquanto o aprendizado em circuito duplo resolve as incompatibilidades das normas da organização, instituindo novas prioridades, ou reestruturando as normas juntamente com as hipóteses e estratégias associadas.

Um modelo de gestão voltado para a aprendizagem organizacional necessita de estruturas organizacionais mais flexíveis, descentralizadas, com atividades desenvolvidas em matrizes que envolvam várias unidades. Motta (1997) argumenta que entre as estruturas imaginadas e criadas para satisfazer às necessidades de tecnologia muito complexa, especialização crescente, criatividade e in- 
terdependência, a que está difundindo-se rapidamente é a estrutura matricial, isto é, estrutura por projetos sobreposta à estrutura funcional.

Uma ferramenta importante da organização aprendiz é a implantação de um sistema de informação que permita a difusão das iniciativas por toda a organização, possibilitando a comunicação dos sucessos de uma unidade para outra ou de uma unidade para a alta gerência. O objetivo do sistema é fazer com que as iniciativas sejam debatidas, e aquelas consideradas estratégicas venham a emergir da organização.

Charan (1991) discorre sobre as networks, sendo que ainda existe confusão sobre o que elas são e como operam. Em algumas empresas, elas representam uma série de relações externas, uma rede global de alianças e joint ventures. Em outras, as networks significam redes informais entre gerentes ou times variáveis, que trabalham independentemente da hierarquia e burocracia. Outras empresas, ainda, definem networks como novas formas de os executivos dividirem informações, usando sistemas de dados gerenciais, videoconferências e outras ferramentas do tipo.

Dessa forma, um modelo de gestão organizacional deve estar fundamentado em algumas diretrizes, como estas: busca da gestão compartilhada para resolução de problemas comuns; transparência para que todos tomem conhecimento do fluxo de informações da organização e possam participar do processo de aquisição do conhecimento; planejamento como instrumento de viabilização de projetos; atribuição de responsabilidades que não provoque incongruências no processo de aprendizagem, mas sirva como motivador para a consecução dos objetivos; e, finalmente, capacitação contínua do corpo funcional da organização.

\section{Conclusóes e ReCOMEndaçóes}

O estudo de caso fornece elementos importantes para a discussão de abordagens teóricas no campo da administração, embora essa frase também possa ser construída de forma inversa, ou seja, as abordagens teóricas contribuem na compreensão e análise de casos. Essa dialética fundamenta a evolução do pensamento em administração. Os estudos sobre estratégia apresentam muitas abordagens, e a construção de estratégias empresariais sofre a influência desses trabalhos. O caso do BACEN é um exemplo de aplicação das ferramentas da escola da gestão estratégica. 
A investigação de corte temporal (a mesma unidade analisada em dois momentos distintos) e de corte organizacional (duas unidades distintas investigadas no mesmo momento) levou à conclusão de que existe uma posição de neutralidade ou mesmo discordância por parte dos gerentes de duas unidades regionais do BACEN, no sentido de que o planejamento estratégico seja suficiente para tornar a organização mais proativa.

O planejamento estratégico não pode ser visto como elemento único, ou até mesmo como principal elemento, do processo de formulação estratégica. Além disso, criar um planejamento muito complicado, cheio de detalhes, extremamente racional, rígido e estruturado, com separação entre pensamento e ação, pode, na verdade, inibir a atividade de prospecção organizacional e conduzir a perdas de oportunidades.

Um modelo de gestão apropriado pode permitir que as estratégias venham a emergir da organização, possibilitando a transformação de ações estratégicas em visões estratégicas. A construção de um modelo de gestão depende da estrutura organizacional, da cultura e dos jogos de poder na organização. Não se pode vislumbrar a implantação de um modelo organizacional, cujas bases estejam vinculadas às escolas de aprendizagem e formulação estratégica ao longo de um caminho, sem imaginar os conflitos de interesse que poderão surgir na organização (a distribuição do poder) e seus impactos na cultura e na estrutura organizacional. Um modelo de gestão que propicie a emergência da estratégia organizacional precisa estar ancorado, como se disse acima, em diretrizes básicas como o gerenciamento compartilhado, a transparência da informação, o planejamento para viabilização de projetos, a atribuição de responsabilidades, sem criar barreiras à aprendizagem e à capacitação do corpo funcional.

\section{NotAs}

${ }^{1}$ Os conceitos foram convertidos em notas, usando o seguinte critério: DT=1 (Discordo Totalmente); $\mathrm{D}=2$ (Discordo); $\mathrm{N}=3$ (Não concordo nem discordo); $\mathrm{C}=4$ (Concordo); $\mathrm{CT}=5$ (Concordo Totalmente), sendo que a questão Q1_4 foi tomada de forma inversa, em função da natureza da pergunta.

${ }^{2}$ Os rótulos Planejamento Estratégico I e II foram definidos nesta pesquisa, e não estão vinculados a nenhum título específico atribuído pela organização. 


\section{ReferênCIAs Biblográficas}

ANSOFF, I. H.

Corporate strategy : an analytic approach to business policy for growth and expansion. New York: McGraw-Hill 1965.

Strategic management. London : MacMillan, 1978.

ANSOFF, I. H.;

MCDONNELL.

\section{Implanting strategic} management. Englewood Cliffs, NJ : Prentice-Hall, 1984.

ARGYRIS, C.;

SCHON, D.

Organizational learning : a theory of action perspective. London : Cambridge, 1993.

AVENIER, M.

La stratégie tâtonnante : des intéractions récursives entre vision et action stratégiques. Aix en Provence : GRASCE, 1996. note de recherche.

Une conception de l'action stratégique en milieu complexe : la stratégie tâtonnante. In: (Org.). La stratégie Chemin Faisant. Paris : Economica, 1997.
BULGACOV, S.

Estudo comparativo e de caso de organizações de estratégias. Organizações e Sociedade, v. 5, n. 11, jan./abr. 1998.

CABRAL, A.

A evolução da estratégia : em busca de um enfoque realista. In: XXII ENCONTRO ANUAL DA ANPAD (1998 : Foz do Iguaçu). Anais Eletrônicos... Foz do Iguaçu : ANPAD, 1998.

CHARAN, R.

How networks reshape organizations for results. Harvard Business Review, Sept./Oct. 1991.

COLLINS, J.;

PORRAS, J.

Building your company's vision. Harvard Business Review, Sept./Oct. 1996.

DAVIDSON, W.

Retailing management. New York : Jonh Wiley \& Sons, 1988.

ENRIQUEZ, E.

$\mathrm{O}$ indivíduo preso na armadilha da estrutura estratégica. ERA, v. 37, n. 1, jan./mar. 1997. 
FISCHER, T.;

GUANAIS, F. C.

Entre planos, projetos e estratégias : o caso Rio sempre Rio. In: XXII ENCONTRO ANUAL DA ANPAD (1998 : Foz do Iguaçu). Anais Eletrônicos... Foz do Iguaçu : ANPAD, 1998.

GIMENEZ, F. A. P.

Escolhas estratégicas e estilo cognitivo : um estudo com pequenas empresas. Revista de Administração Contemporânea, v. 2, n. 1, p. 27-45, jan./abr. 1998.

\section{GIMENEZ, F. A. P. et al.}

Estratégias em pequenas empresas : uma aplicação do modelo de Miles e Snow. In: XXII ENCONTRO ANUAL DA ANPAD (1998: Foz do Iguaçu). Anais Eletrônicos... Foz do Iguaçu : ANPAD, 1998.

HAMEL, G.

Strategy as revolution. Harvard Business Review, July/Aug. 1996.

HAMEL, G.;

PRAHALAD, C. K.

Strategic intent. Harvard Business Review, May/June 1989.

HICKMAN, C.;

SILVA, M.

Creating excellence : managing corporate culture, strategy, and change in the new age. New York : NAL Books, 1984.

HOFER, C. W.;

SCHENDEL, D.

Strategy formulation : analytical concepts. New York : West Publishing, 1978.

HORWITCH, M.

A estratégia empresarial. In: - Administração de empresas : estratégias e direção. Nova Cultural, 1988.

\section{LAURIOL, J.}

Une analyse des représentations de la stratégie et de son management dans la production d'ouvrages en langue française. Journée Recherche, oct. 1996.

MCCRAW, T. K.

Alfred Chandler : ensaios para uma teoria histórica da grande empresa. Rio de Janeiro : Editora da FGV, 1998.

MINTZBERG, $\mathrm{H}$.

The design school : reconsidering the basic premises of strategic management. Strategic Management Journal, v. 11, p. 171-195, 1990.

The rise and fall of strategy planning. Englewood Cliffs, NJ : Prentice-Hall, 1994. 
MINTZBERG, H.;

WATERS, J.

Of strategies, deliberate and emergent. In: DAVID, A.; BOWMAN, C. (Eds.). Readings in strategic management. London : MacMillan, 1985.

MORAES, A. M.

$O$ planejamento estratégico no Banco Central do Brasil e a viabilidade estratégica em uma unidade descentralizada da autarquia : um estudo de caso. Belo Horizonte, 1995. Dissertação (Mestrado)-Universidade Federal de Minas Gerais.

MORGAN, G.

Imagens das organizações. São Paulo : Atlas, 1985.

MOTTA, F.

Teoria geral da administração. 21. ed. São Paulo : Pioneira, 1997.

NOGUEIRA, A. R. R.;

MOREIRA, P. C. A.

$\mathrm{O}$ alinhamento estratégico e a construção do futuro : um estudo exploratório. Revista de Administração Contemporânea, v. 2 , n. 2, p. 103-125, maio/ago. 1998.

PETERS, T.;

WATERMAN, $\mathrm{H}$.

In search of excellence : lessons from America's best run companies. New York : Harper \& Row, 1982.

PORTER, M.

Estratégia competitiva. São Paulo: Campus, 1986.

What is strategy? Harvard Business Review, Nov./Dec. 1996.

PRAHALAD, C. K.;

HAMEL, G.

The core competence of the corporation. Harvard Business Review, p. 79-91, May/June 1990.

QUINTELLA, R.

The strategic management of technology in the chemical and petrochemical industries. London : Printer, 1993.

QUINTELLA, R.;

DIAS, C.

Trends in international business thought and literature : business strategy in Brazil - how a definition may help. The International Executive, v. 39, n. 3, May/June 1997.

SENGE, $P$.

A quinta disciplina : arte, teoria e prática da organização de aprendizagem. São Paulo: Campus, 1990. 